\title{
Dermatoglyphic Pattern Differences in Females with Reproductive System Cancers and It's Scope in Preventive Care
}

\author{
P. Sofia', Subhadra Devi Velichety ${ }^{2}$, P. A. Chandrasekharan ${ }^{3}$, G. Ravi Prabhu ${ }^{4}$ \\ ${ }^{1}$ Assistant Professor, Rajiv Gandhi Institute of Medical Sciences, Kadapa, Andhra Pradesh, ${ }^{2}$ Professor \& Head, Department of Anatomy, SVIMS - Sri \\ Padmavathi Medical College for Women, Tirupathi, Andhra Pradesh, ${ }^{3}$ Professor, Department of OBG , S.V. Medical \\ College, Tirupathi, ${ }^{4}$ Professor \& HOD, Department of SPM, S.V. Medical College, Tirupathi.
}

\section{Abstract}

Introduction: Female reproductive system cancers shorten lifespan in women because of high mortality and morbidity. The detection of pre-invasive and micro-invasive stages makes near $100 \%$ survival of cancer patients. Dermatoglyphics is the scientific study of fingerprints. Many genes which take part in the control of finger and palm dermatoglyphic development distinguished cancer patients from the general population. It is possible that these genes also predispose to the development of malignancy. Since many investigations are needed to confirm the diagnosis of cancers, dermatoglyphics can be used as a screening procedure for planning preventive care if a specific pattern is known for a cancer. Aims and Objectives: To analyze the prints of different cancers, to analyze the results, compare with controls and observe the differences in main parameters of dermatoglyphic patterns and to determine a specific pattern for specific cancers. Subjects and Methods: This is a prospective, observational and an analytical study started after the approval by Institutional Ethical Committee of S.V. Medical College, Tirupati. The material for the study consisted of finger and palm prints of outpatients and inpatients of the Department of OBG, Tirupati, Cancer Hospital in and around Tirupati, Nellore and Kadapa. The ink prints of each finger and palm were collected and analyzed. Results: Ridge counts, digital patterns and main line formulae observed in different cancers in the present study were analyzed and presented. Mean TFRC was higher in normal group. Greater AFRC was observed in cancer cervix patients when compared to controls. In the present study, there is no difference ( $p>0.05)$ in a-b ridge count among carcinoma of cervix and control group in both hands. Differences of mean atd, tad and tda angles among the groups are not statistically significant $(\mathrm{P}>0.05)$. The most common Cmain line termination pattern of cancers are $\mathrm{U}$ followed by $\mathrm{R}$ and then $\mathrm{Ab}$. IV interdigital area of both hands presented less incidence of loop pattern in cancer cases when compared to normal group. Special findings in respective cancers are discussed separately and they are not found in any other literature. Conclusion: There are very limited studies in literature on dermatoglyphic pattern in female reproductive cancers. Though the cost of prints is less, more time and skilled human resources are required for their analysis. Study sample size of controls and cases to be increased. Public should be enlightened about dermatoglyphics. If large number of studies are done and a specific pattern is established for specific cancers, then it becomes cost-effective to people so that a risk is predicted beforehand in any disease and preventive methods can be employed at an early age as the dermatoglyphic patterns do not change in a life time.

Keywords: Arches; cervical cancer; C-main line termination; composites; dermatoglyphics; digital patterns; female reproductive system; hypothenar area; interdigital patterns; loops; Main line formula; Main line index; Ridge count; thenar area; Whorls.

Corresponding Author: Dr. P. Sofia, Assistant Professor, Department of Anatomy, Rajiv Gandhi Institute of Medical Sciences, Kadapa.

Received: November 2018

Accepted: December 2018

\section{Introduction}

The term Cancer is coined by Hippocrates, the father of medicine. He used the term cancer derived from 'carcinos' for non-healing ulcers. Carcinos means 'Crab'. The estimated cancer cases around the world in 2008 were 6.6 million with an almost equal incidence between sexes. ${ }^{[1]}$ The number is expected to increase to 21 million by year 2030.They remain main killers in developing countries like India. It forms major health problem despite it being potentially preventable.

The gynecological cancers in the world are estimated to be 153,$850 ; 167,658$ and 182,602 for the years 2010,2015 and 2020 respectively. Among these, for the year2020, cancers of cervix $(123,291 ; 67.5 \%)$, ovary $(36,199 ; 19.8 \%)$ and corpus uteri $(17,533 ; 9.6 \%)$ are expected to contribute maximum in their decreasing order. ${ }^{[2]}$ Next to the breast cancer $(22.9 \%)$, the commonest female reproductive system cancers are the cancer cervix $(8.8 \%)$, uterine endometrium $(4.8 \%)$ and ovary $(3.7 \%) .^{[1]}$

Dermatoglyphics is the scientific study of fingerprints. ${ }^{[3]}$ The analysis of ridge patterns by studying prints of fingers is known as dermatoglyphics. ${ }^{[4]}$ Dermatoglyphics has been studied for fortune telling by palmists and as a definitive and unalterable tool for identification by forensic experts. Medical interest in epidermal ridges developed only in the last few decades when it became apparent that many patients with chromosomal aberrations had unusual ridge patterns. $17^{\text {th }}$ century Western anatomists noted abundance of large 
pores of sweat glands on crests of ridges and also studied the arrangements of ridges on fingers and palms. ${ }^{[5]}$ The scientific way of studying dermatoglyphics appears to be only since 1684. The first official mentioning of fingerprints was about the interesting markings found on the human fingertips in 1684. Absence of epidermal ridges is extremely rare. ${ }^{[4]}$

Dermatoglyphics of many conditions like schizophrenia, Down's syndrome, Diabetes Mellitus, hypertension and epilepsy have been studied. Dr. Theodore J. Berry in his book "The hand as a mirror of systemic disease" has associated dermatoglyphics with 50 diseases both congenital and acquired.

Cancer-related genes can fall in to two major categories. They are oncogenes that have a dominant effect and tumor suppressor genes with a recessive phenotype. It is suggested that many genes which take part in the control of finger and palm dermatoglyphic development distinguished cancer patients from the general population. ${ }^{[6]}$ It is possible that these genes also predispose to the development of malignancy. ${ }^{[7]}$

Since many investigations are needed to confirm the diagnosis of cancers, dermatoglyphics can be used as a screening procedure to define indications for laboratory procedures which are complex and expensive. Dermatoglyphics can be efficiently employed with other clinical signs as a preliminary investigative procedure.

In view of above foresaid considerations, an attempt to find the relation between the finger prints and the cancers can be tried so that any common patterns if found in the patients, will be of great significance giving a notion as high-risk case for whom preventive screening methods can be advised.

\section{Aims \& Objectives:}

- This is an observational study conducted with an objective of observing different dermatoglyphic patterns in various cancers of female reproductive system.

- To study various patterns of finger prints in women with genital system cancers and establish digital pattern differences in each cancer.

- To compare patterns of palmar prints of cases with controls and to find out whether there exist a specific dermatoglyphic trait for each cancer and its significance.

\section{Subjects and Methods}

This is a prospective, observational and an analytical study started after the approval by Institutional Ethical Committee of S.V. Medical College, Tirupati, Andhra Pradesh, India. The material for the study consisted of finger and palm prints of outpatients and inpatients of the Department of OBG, Tirupati, Cancer Hospitals in and around Tirupati, Nellore and Kadapa. Finger and palmar dermatoglyphic patterns of 76 normal control females and 76 females with different genital system cancers were recorded, morphological parameters were observed, morphometric patterns were measured and the results were statistically analyzed. Among the 76 cancer cases, number of females with different reproductive cancers is cancer cervix (49); endometrium (7); ovary (11); Vulva (3); Vagina (3); fallopian tube (1) and cervix and vagina (2). The ink prints of each finger and palm were collected and analyzed for the following parameters as per Ink method, first identified by Cummins and Midlow.

Quantitative measurements on the digits involved ridge counts between fixed points. Since one of the fixed points was a triradius, the measurement was not independent of pattern type. Arches, which lack a triradius, always have a ridge count of zero. Loops, with one triradius, have one count and whorls, with two triradii, use the higher of two counts (Fig.1).

Ridge Count (rc): When a line is drawn from the triradius to the center of the pattern, the number of intersected ridges present between these two gives the ridge count.

Total Finger Ridge Count (TFRC): The total sum of larger counts of 10 digits.

Absolute Finger Ridge Count (AFRC): The addition of ridge counts of both radial and ulnar loops over fingers.

TFRC determines the size of pattern and AFRC determines both pattern size and pattern intensity at same time.

a-b ridge count (a-b rc): digital triradii are marked at the bases of digits and are called a, b, c, d [Figure 1]. a-b ridge count is the number of ridges between the triradii $a$ and $b$.

Atd, tad, tda angles: [Figure 1]

atd angle: It is the angle drawn between triradius $t$, triradii a and d. It measures relationship of length of hand to width.

atd angle measurement: Angle is measured by a protractor. It is the axial triradius of the palm. a and $d$ are the point of digital triradii of little and index finger respectively. When the three points are joined, they form a triangle. So, the angles are measured in between them constituting 3 angles

- $\quad$ atd angle, which is commonly used

- tad angle

- tda angle

C-main line termination -MAIN - LINE FORMULA: [Figure2]

The longest of the three radiants of any of the triradii with a, $\mathrm{b}, \mathrm{c}$ and $\mathrm{d}$ is directed towards the centre of a palm or sole and usually ends in a margin. Mainlines of d, c, b, a are called D, C, B, A. The formula is written as DCBA.

Purpose: To depict the general direction of ridges which differ between right and left side, between different individuals and different populations. They were classified as ulnar, radial, proximal and absent types.

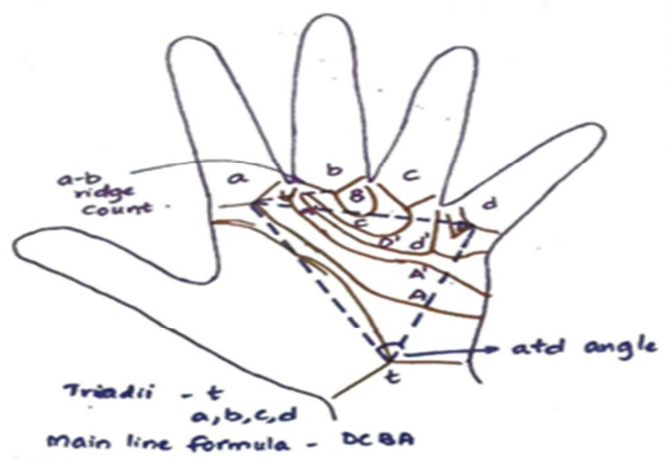

Figure 1: showing the palmar dermatoglyphic pattern measurements - atd, tad, tda angles, ridge counts 


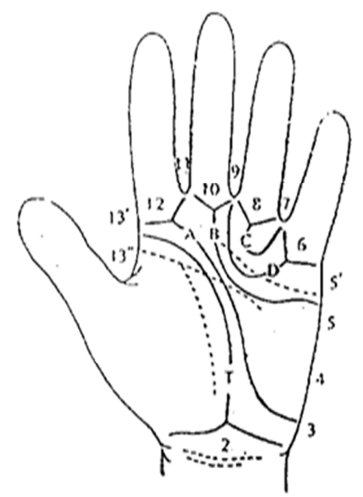

(a)

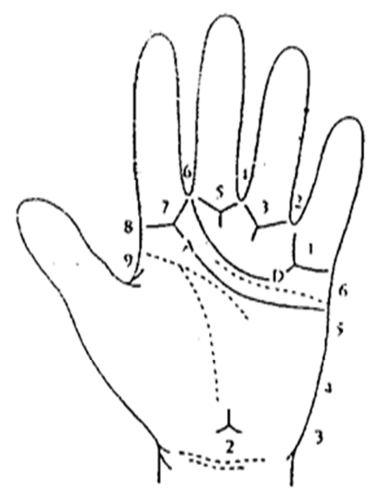

(b)

Figure 2: Showing main line formula.

\section{Results}

Total Finger Ridge Count (TFRC) and Absolute Finger Ridge Count (AFRC):

Mean TFRC was higher in normal group (114.2) when compared to cancer cervix (112.7) and other cancers (102.1) groups. Mean Absolute Finger Ridge Count (AFRC) was higher in cancer cervix (151.8) compared to normal group (146.7) and other cancers group (133.7). However, the differences in the mean TFRC and AFRC among the various groups are found to be not statistically significant $(\mathrm{P}>0.05$; NS). Greater AFRC was observed in cancer cervix patients when compared to controls. In other cancers, AFRC is lesser than that of controls and cancer cervix patients but the difference is not statistically significant.

\section{a-b ridge count $(a-b$ rc):}

No significant difference was reported for a-b ridge count in carcinoma of cervix and control group in literature. In the present study, there is no difference $(p>0.05)$ in $a-b$ ridge count among carcinoma of cervix and control group in both hands. In the present study when analysed separately for normal, cancer cervix and other cancer cases, a-b rc was greater on right side than left side in controls.

atd, tad, tda angles:

Mean atd angle showed no difference between groups and sides. On the right side this angle was higher in normal group (45.2) than cancer cervix group (44.2) and also in other cancers (43.5). Left hand mean atd angle was higher in normal group (46.0) than cancer cervix group (44.5) and other cancers (43.5). Mean tad angle is same in all the groups on right side and slightly higher in other cancer group on left side. Mean tda angle -higher on right side in other cancers (78.9) and on left side in cancer cervix group (80.3). Differences of mean atd, tad and tda angles among the groups are not statistically significant $(\mathrm{P}>0.05)$.

\section{C-Main Line Termination (CMLT)}

In control group commonest pattern of CMLT in right and left hands are $\mathrm{R}$ followed by $\mathrm{U}$ and $\mathrm{Ab}$ in an order. In cancer cervix group it is same as that of controls on right side. In other cancers group the commonest pattern on right side was $\mathrm{U}$ followed by $\mathrm{R}$ and then $\mathrm{Ab}$ in an order. In the left hand similar pattern of $\mathrm{U}$ followed by $\mathrm{R}$ and then $\mathrm{Ab}$ in both types of cancer groups. Differences in the proportions among the various groups are not found to be statistically significant.

\section{Main line formula (MLF):}

The commonest MLF pattern [DCBA] was different between hands and between normal and cancer groups though the patterns are not statistically significant. In right hand in normal group it was 11-9-7-5 >9-7-5 -5 >11-9-7-5, while among cancer cervix group and other cancer groups, the commonest patterns were 9-7-5-5, >11-9-7-5. In left hand in normal group was found to be 9-7-5'-5 >11-9-7-5 > $7-6-5$ ' -5 in that order. In the cancer cervix \& other cancers also, the first two common patterns are found to be similar to normal group. The third common pattern in cancer cervix was found to be $7-5-5$ ' -5 while in other cancers, it was found to be $11-9-5$ ' -5 . So, we can say main line formula cannot determine the predisposition of cancer.

\section{Interdigital areas:}

4th interdigital area of both hands presented less incidence of loop pattern in cancer cases when compared to normal group. But the differences were not significant statistically. In the thenar area commonest pattern observed was arch in both hands with a higher value for cancer patients with no statistically significant differences between the groups.

Ridge counts, digital patterns and main line formulae observed in different cancers in the present study were analyzed and presented and could not be compared with any study as there were no reports on these lines in the literature. In addition to the above discussed features, the following special findings were observed in the present study for each of the female reproductive cancers.

\section{Cancer cervix-special findings}

- The mean TFRC is 112.71 and AFRC is 151.79 .

- The MLF is 11-9-7-5 (32.6\%), 9-7-5 -5(24.4\%) \& 7-5 - $5^{-}$$5^{`}(8.1 \%)$

- Mostly bilaterally symmetrical.

- On fourth finger of left hand, whorls are mainly the digital patterns.

- The digital tip patterns in all digits are more than 3 Whorls.

\section{Cancer endometrium-special findings:}

- The mean TFRC is 133.14 and AFRC is 107.09.

- The MLF is mostly 9-7-5`-5.

- On little finger of right hand, only ulnar loop is present constantly.

- On thumb of left hand, only whorl or composites are present.

- The digital tip patterns in all digits are more than 3 Whorls.

Cancer ovary-special finding:

- The mean TFRC is 85.54 and AFRC is 176.28.

- The MLF is mostly 9-7-5 -5 .

- 2 loop patterns are seen in fourth interdigital areas of both hands more common on left hand.

- Arches are not associated with patterns in palmar areas and are irregular patterns.

- No patterns in first and second interdigital areas of both hands.

- The digital tip patterns in all digits are more than 3 Whorls.

- The MLF is mostly 11-9-7-5 (50\%)

- Bilaterally symmetrical 
Cancer vagina-special findings:

- The mean TFRC is 89.3 and AFRC is 124.6.

- The MLF is mostly 9-7-5-5.

- Specific digital pattern noted.

- On thumb and middle fingers of both hands, only whorl or arches are present.

- On little finger of left hand, only ulnar loop is present constantly.

- On index and ring fingers of both hands, only whorl or composites are present.

- Whorls are more.

\section{Cancer cervix and vagina-special findings:}

- The mean TFRC is 119.3 and AFRC is 167.3.

- The MLF is mostly 9-7-5 `-5 and bilaterally symmetrical. If asymmetrical, then contains both 11-9-7-5 and 9-7-5 -5.

- Specific digital tip pattern is noted.

- On little finger of left hand, only ulnar loop is present constantly.

- On index and ring fingers of both hands, only whorl or composites are present.

- Loop patterns are seen in third interdigital areas of right hand and third and fourth interdigital areas of left hand and arch patterns on thenar area of both hands.

- Whorls are more.

\section{Cancer vulva-special findings:}

- The mean TFRC is 122 and AFRC is 152.

- 50\% have 11-9-7-5.

- If bilaterally symmetrical, then the digital patterns are also symmetrical.

- Ulnar loops are more.

\section{Cancer fallopian tube-special findings:}

- The mean TFRC is 14 and AFRC is 18.

- The MLF is mostly 11-9-7-5.

- $70 \%$ of digital tip patterns are arches. Bilaterally symmetrical

- Loop patterns are seen in third interdigital areas of both hands and third and arch patterns on thenar area of both hands.

\section{Discussion}

In all cancer patients, left hand values are less than right hand values in mean atd angles. Atd angles in cancers are less than normal average angle suggesting that a low atd angle may predispose to cancer. Based on the present study, it can be stated that $\mathrm{C}$-main line when terminated to ulnar side can be a predisposing factor for cancer. The commonest patterns of MLF in cancers were 9-7-5-5, 11-9-7-5 and 7$5-5 `-5$ ?

In the present study, the fourth interdigital area of both hands presented a less incidence of loop pattern in cancer cases when compared to normal group. In the thenar area, the commonest pattern observed was arch in both hands with a higher value for cancer patients.

Reddy, ${ }^{[8]}$ observed significant difference in frequency of presence of pattern in I, II, \& IV interdigital areas. Pal, ${ }^{[9]}$ observed this difference for only III interdigital area. Inamdar, ${ }^{[10]}$ and Kasinathappa, ${ }^{[11]}$ did not observe any difference in the frequency of presence of pattern in all 5 interdigital areas in carcinoma of cervix group. So, the present study has to be extended to a large population study for the pattern present in IV interdigital area and find the difference in patterns.

TFRC is increased in the studies of Reddy and Inamdar. ${ }^{[8,10]}$ Kasinathappa`s, ${ }^{[1]}$ study has revealed a significant increase in TFRC in patients as compared to controls. The present study has correlated with the study of Pal, ${ }^{[9]}$ and Kalpana, ${ }^{[12]}$ as TFRC is decreased in cancer cervix patients. So, it can be said that pattern intensity shows that Indian women who will be having less TFRC will be vulnerable to female genital system cancers. Aprajitha, ${ }^{[13]}$ reported that the lower values of TFRC $(<50)$ were associated with the breast cancer patients when compared to controls $(>126)$. This suggests that lower values of TFRC $<50$ are seen in cancers. If it is generalised to all cancers, then it can be attributed to other cancers also. If it is attributed to all cancers in the present study also, TFRC less than 126 was observed.

A significant increase in AFRC in carcinoma of cervix group as compared to control group was observed in Kasinathappa`s, ${ }^{[1]}$ study. AFRC is increased in cancer cervix, endometrium, vulva and combined cervix and vaginal cancer in the present study. So, it can be said that Indian women who will be having more AFRC will be vulnerable to female genital system cancers.

Inamdar, ${ }^{[9]}$ also has not observed any significant difference in $\mathrm{a}-\mathrm{b}$ ridge count in carcinoma of cervix and control group. The left-hand values are higher than the right-hand values in normal. ${ }^{[14]}$ The present study coincides with it. But in cancer endometrium, vagina and vulva, right values are higher. So, it can be said that $\mathrm{a}-\mathrm{b}$ ridge count may not have any relation with cancers unless it is proved in a large population.

\section{Conclusion}

As there are very limited studies in literature on dermatoglyphic pattern in female reproductive cancers, the sensitivity and specificity of cancers cannot be estimated. Though the cost of prints is less, more time and skilled human resources are required for their analysis. Because of cost and sophisticated facilities required for establishing digitalized equipment for analyzing finger prints, it can only be done in well-established institutions.

To adopt dermatoglyphics as a screening test, public should be enlightened about dermatoglyphics. Study sample size of controls and cases to be increased for accurate estimation of statistical parameters of sensitivity, specificity, odds ratios, positive predictive value and negative predictive value etc. that are specific to a disease.

If cost effective, easy to use software are designed and used for large sample screening by health organizations the data can be used for predicting the possible risk of diseases. Then it becomes cost-effective to people so that a risk is predicted beforehand in any disease and preventive methods can be employed.

\section{Limitations of the study:}




\section{Safia et al; Dermataglyphic Pattern Differences in Females with Repraductive System Cancers}

- Study period is limited.

- Sample size is less.

- Follow up of controls is not feasible.

- Variations in the prevalence of different cancers led to unequal number of different types of cancers.

- Volunteers for study were less because of lack of awareness.

- Because study is tertiary care hospital based, study may not reflect the phenomenon in general population.

\section{References}

1. Ferlay J, Shin HR, Bray F, Forman D, Mathers C liable and Parkin DM. GLOBOCAN 2008 v2.0, Cancer Incidence and Mortality Worldwide: IARC Cancer Base No. 10 [Internet]. Lyon, France: International Agency for Research on Cancer; 2010. Available from: http://globocan.iarc.fr, accessed on 27/9/13.

2. Takiar R, DeenuNadiyal. Projections of Cancer Cases in India (20102020) by Cancer Groups. Asian Pacific Journal of Cancer Prevention, 2010;11:1045-49. http:// www. apocpcontrol.com/paper_file/issue_abs/Volume11_No4/c104549\%20Takiar.pdf.

3. Cummins. Epidermal ridge configurations in developmental defects, with particular reference to the ontogenetic factors which condition ridge direction. Am J Anat 1926;38: 8-151.
4. Susan Standring. Gray`s Anatomy. Skin and its appendages. Mary-clare C, Miller. Fortieth edition. Elsevier. London; 2008:145-154.

5. Mukherjee DP. How scientists read palms. Science Today 1980 Jun; p.15-21.

6. Penrose LS, Loesch D. Dermatoglyphics sole patterns. A new attempt at classification. Hum Biol 1969; 41:427-448.

7. FullerIC.Dermatoglyphics: A Diagnostic aid? J MedGenet1973; 10:165-169.

8. ReddySS,AhujaYR, ReddyOS. Dermatoglyphic studiesincarcinoma ofthecervix. Indianjournal of heredity, 1977; 9:35-40

9. PalGP, RoufalRV, BhagwatSS. Dermatoglyphics incarcinoma cervix. Journal of anatomical society of India 1985;34(3):157-161.

10. Inamdar VV, Vaidya SA, Kulkarni P, Devarshi DB, Kulkarni S, Tungikar. Dermatoglyphics in carcinoma of cervix. Journal of Anatomical society of India 2006;55(1):57-59

11. Kasinathappa, KhanzodeLataS. Study of palmar dermatoglyphics in carcinoma of cervix. Int J Cur Res Rev 2013 Feb; 05:04.

12. Kalpana Vishnu Patil. Dermatoglyphic in the carcinoma of cervix [Golden Jubilee Abstracts]. J. Anat. Soc. India 2003;52(1):82-115.

13. Aprajita, Vishwas. A cross-sectional study on the palmar dermatoglyphics in relation to carcinoma breast patients. Journal of clinical and diagnostic research 2013;1-4.

14. Kobyliansky, Eugene, Bejerano M, Yakovenko K, and Katznelson MB. "Relationship between genetic anomalies of different levels and deviations in dermatoglyphic traits. "Studies in Historical Anthropology 4, no. 2004 (2006):61-121.

Copyright: () the author(s), publisher. Academia Anatomica International is an Official Publication of "Society for Health Care \& Research Development". It is an open-access article distributed under the terms of the Creative Commons Attribution Non-Commercial License, which permits unrestricted non-commercial use, distribution, and reproduction in any medium, provided the original work is properly cited.

How to cite this article: Sofia P, Velichety SD, Chandrasekharan PA, Prabhu GR. Dermatoglyphic Pattern Differences in Females with Reproductive System Cancers and It's Scope in Preventive Care. Acad. Anat. Int. 2018;4(2):32-36.

DOI: dx.doi.org/10.21276/aanat.2018.4.2.9

Source of Support: Nil, Conflict of Interest: None declared. 